\title{
Punching Tests of Slabs with Low Reinforcement Ratios
}

\author{
by Stefano Guandalini, Olivier L. Burdet, and Aurelio Muttoni
}

\begin{abstract}
The results of a test series on the punching behavior of slabs with varying flexural reinforcement ratios and without transverse reinforcement are presented. The aim of the tests was to investigate the behavior of slabs failing in punching shear with low reinforcement ratios. The size of the specimens and of the aggregate was also varied to investigate its effect on punching shear. Measurements at the concrete surface as well as through the thickness of the specimens allowed the observation of phenomena related to the development of the internal critical shear crack prior to punching. The results are compared with design codes and to the critical shear crack theory. From that comparison, it is shown that the formulation of ACI 318-08 can lead to less conservative estimates of the punching strength for thick slabs and for lower reinforcement ratios than in the test results. Satisfactory results are, on the other hand, obtained using Eurocode 2 and the critical shear crack theory.
\end{abstract}

Keywords: aggregate size; critical shear crack theory; punching shear; reinforcement ratio; size effect.

\section{INTRODUCTION}

Punching shear is usually the governing failure mode for flat slabs supported on columns, with or without capitals. This subject has been thoroughly investigated in the past by various researchers dealing with the theoretical and/or experimental aspects of the phenomenon. ${ }^{1-6}$

Current design code provisions for checking punching shear follow a format similar to that of ACI $318-08^{7}$ (Eq. (1)), which relates the punching shear strength $V_{R}$ to the effective flexural depth of the slab $d$ and the control perimeter $b_{0}$ of a critical section (at a distance $d / 2$ from the face of the column for ACI 318- $08^{7}$ ) and the concrete compressive strength $f_{c}$. According to ACI $318-08,{ }^{7}$ the strength is proportional to the square root of the specified concrete compressive strength $f_{c}^{\prime}$. For approximately square columns where the ratio $b_{0} / d$ is sufficiently small, the punching shear strength is

$$
\begin{gathered}
V_{A C I}=\frac{1}{3} b_{0} d \lambda \sqrt{f_{c}^{\prime}} \quad \text { (in SI units; MPa, mm) } \\
V_{A C I}=4 b_{0} d \lambda \sqrt{f_{c}^{\prime}} \quad \text { (in U.S. customary units; psi, in.) }
\end{gathered}
$$

where $\lambda$ is the modification factor for lightweight concrete, taken as unity for normalweight concrete in the present paper.

Other codes, such as Eurocode 2, ${ }^{8}$ include additional parameters such as the flexural reinforcement ratio $\rho$ or the thickness $d$ of the slab

$$
\begin{gathered}
V_{E C 2}=0.18 b_{0, E C 2} d \xi\left(100 \rho f_{c}{ }^{\prime}\right)^{1 / 3} \text { (in SI units; MPa, mm) } \\
V_{E C 2}=5 b_{0, E C 2} d \xi\left(100 \rho f_{c}^{\prime}\right)^{1 / 3} \text { (in U.S. customary units; psi, in.) }
\end{gathered}
$$

where $b_{0, E C 2}$ is the control perimeter located at a distance $2 d$ from the face of the column, $\rho$ is the flexural reinforcement ratio, and $\xi$ is a factor accounting for size effect (decreasing nominal shear strength with increasing size of the member), whose value can be obtained as

$$
\xi=1+\sqrt{\frac{200 \mathrm{~mm}}{d}}\left(\xi=1+\sqrt{\frac{7.87 \mathrm{in}}{d}}\right) \leq 2.0
$$

Figure 1 shows the design strength of flat slabs predicted by ACI $318-08^{7}$ and Eurocode $2^{8}$ as a function of the longitudinal reinforcement ratio. It can be noted that the punching shear strength according to ACI $318-08^{7}$ (Eq. (1)) does not include the amount of flexural reinforcement, and thus yields a constant strength (horizontal plateau in Fig. 1) for members where punching shear is governing. For cases where the flexural reinforcement ratio is very small, the flexural capacity of the slab governs the strength (shown by the almost linear increase in the strength with increasing flexural reinforcement ratio in Fig. 1). The flexural capacity is not directly specified in the Code, but it was determined herein on the basis of the direct design method of ACI 318-08. ${ }^{7}$ According to Fig. 1, slabs with a reinforcement ratio over the column larger than approximately $0.3 \%$ should be able to fully develop the punching shear strength given by ACI 318-08. ${ }^{7}$

The approach of Eurocode $2^{8}$ also limits the strength of a slab with small reinforcement ratios. Because Eurocode $2^{8}$

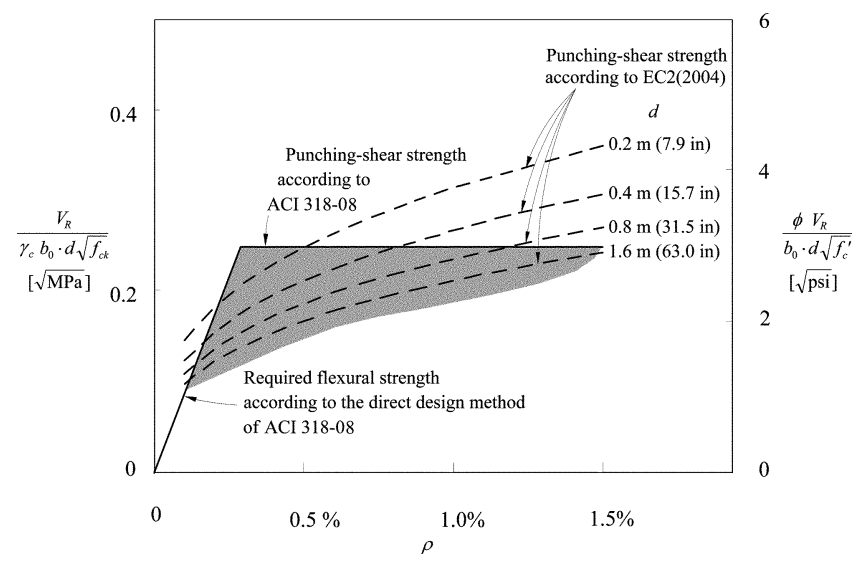

Fig. 1-Influence of flexural reinforcement ratio on punching shear strength according to ACI $318-08^{7}$ and Eurocode $2^{8}$ $\left(\mathrm{f}_{\mathrm{ck}}=30 \mathrm{MPa}(4350 \mathrm{psi}), \mathrm{f}_{\mathrm{yk}}=414 \mathrm{MPa}(60 \mathrm{ksi})\right.$, interior column $\left.\mathrm{c} / \mathrm{d}=1, \ell / \mathrm{d}=25, \ell_{1}=\ell_{2}\right)$.

ACI Structural Journal, V. 106, No. 1, January-February 2009.

MS No. S-2007-230 received June 15, 2007, and reviewed under Institute publication policies. Copyright () 2009, American Concrete Institute. All rights reserved, including the making of copies unless permission is obtained from the copyright proprietors. Pertinent discussion including author's closure, if any, will be published in the November-December 2009 ACI Structural Journal if the discussion is received by July 1, 2009. 
Stefano Guandalini is a Structural Engineer at Lurati Muttoni Partner, Mendrisio, Switzerland. He received his diploma in civil engineering from the Swiss Federal Institute of Technology, Zurich, Switzerland, in 1996, and his PhD from the École Polytechnique Fédérale de Lausanne (EPFL), Lausanne, Switzerland, in 2005

Olivier L. Burdet is a Senior Researcher and Lecturer at EPFL. He received his diploma in civil engineering from EPFL in 1983 and his PhD from The University of Texas at Austin, Austin, TX, in 1990. His research interests include the serviceability behavior of structures and the modeling of the behavior of concrete structures using stress fields.

ACI member Aurelio Muttoni is a Professor and Head of the Structural Concrete Laboratory at EPFL. He received his diploma and PhD in civil engineering from the Swiss Federal Institute of Technology, Zurich, in 1982 and 1989, respectively. His research interests include the theoretical basis of the design of reinforced concrete structures, shear and punching shear, fiber-reinforced high-strength concrete, soilstructure interaction, and the conceptual design of bridges.

includes the amount of flexural reinforcement and the depth of the slab in its punching shear formulation (Eq. (2)), however, a family of design curves for punching shear (dashed lines in Fig. 1) are obtained with an increasing load capacity as the amount of flexural reinforcement increases.

Neglecting the effect of the amount of reinforcement, as in the ACI Code, ${ }^{7}$ is conservative for large reinforcement ratios, as shown in Fig. 1. For slabs with low reinforcement ratios where the punching shear strength is governing, however, the ACI design equation ${ }^{7}$ predicts strengths that are clearly larger and less conservative than those given by Eurocode $2^{8,9}$ (shaded area in Fig. 1). This overestimation increases with the slab thickness. Investigating the punching strength of slabs with low reinforcement ratios (indicated by the shaded area in Fig. 1) is thus of great interest, because it covers designs according to the direct design method (or similar approaches) for which ACI $318-08^{7}$ may overestimate the punching strength.

Experimental testing in punching of slabs with low reinforcement ratios has been scarce in the past, as researchers usually try to avoid any flexural failure during their tests, and thus a majority of tests have been performed on specimens with fairly large amounts of flexural reinforcement. While this can be meaningful for testing purposes, ${ }^{10}$ it should be accompanied by corresponding requirements in design codes, specifying a similar amount of flexural reinforcement in actual designs. As Fig. 1 shows, however, practical designs typically use lower amounts of flexural reinforcement over the columns of flat slabs.

This paper presents the results of a test campaign on the behavior of slabs without punching shear reinforcement failing in punching shear with low reinforcement ratios (shaded area in Fig. 1) and compares these results with those of slabs with larger reinforcement ratios. In addition to the effect of the reinforcement ratio, the series also studies the influence of size effect on punching shear by including tests with three specimen sizes with the slab thicknesses varying from 0.125 to $0.5 \mathrm{~m}$ (4.9 to $19.7 \mathrm{in}$.). The influence of the aggregate size and of the ductility of the reinforcement are also investigated in this test series. The results are compared with the results of design codes and with the critical shear crack theory $9,11,12$ (whose fundamentals are given in the Appendix).

\section{RESEARCH SIGNIFICANCE}

This paper presents the results of an experimental test campaign on the punching shear strength of slabs in which the reinforcement ratio, the thickness of the slab, and the maximum aggregate size were varied. The tests focus mainly on slabs with low reinforcement ratios (but whose values are usually found in practice), where scanty experimental data are currently available. The results show that design codes that do not account for the amount of the flexural reinforcement ratio and size effect may lead to significantly unsafe estimates of the punching shear strength for such cases.

\section{EXPERIMENTAL PROGRAM}

The test series was mainly conceived to investigate the shaded area of Fig. 1, with some tests exploring the domain of larger reinforcement ratios and others with very low reinforcement ratios, investigating the mode of failure in presence of yielding of the flexural reinforcement.

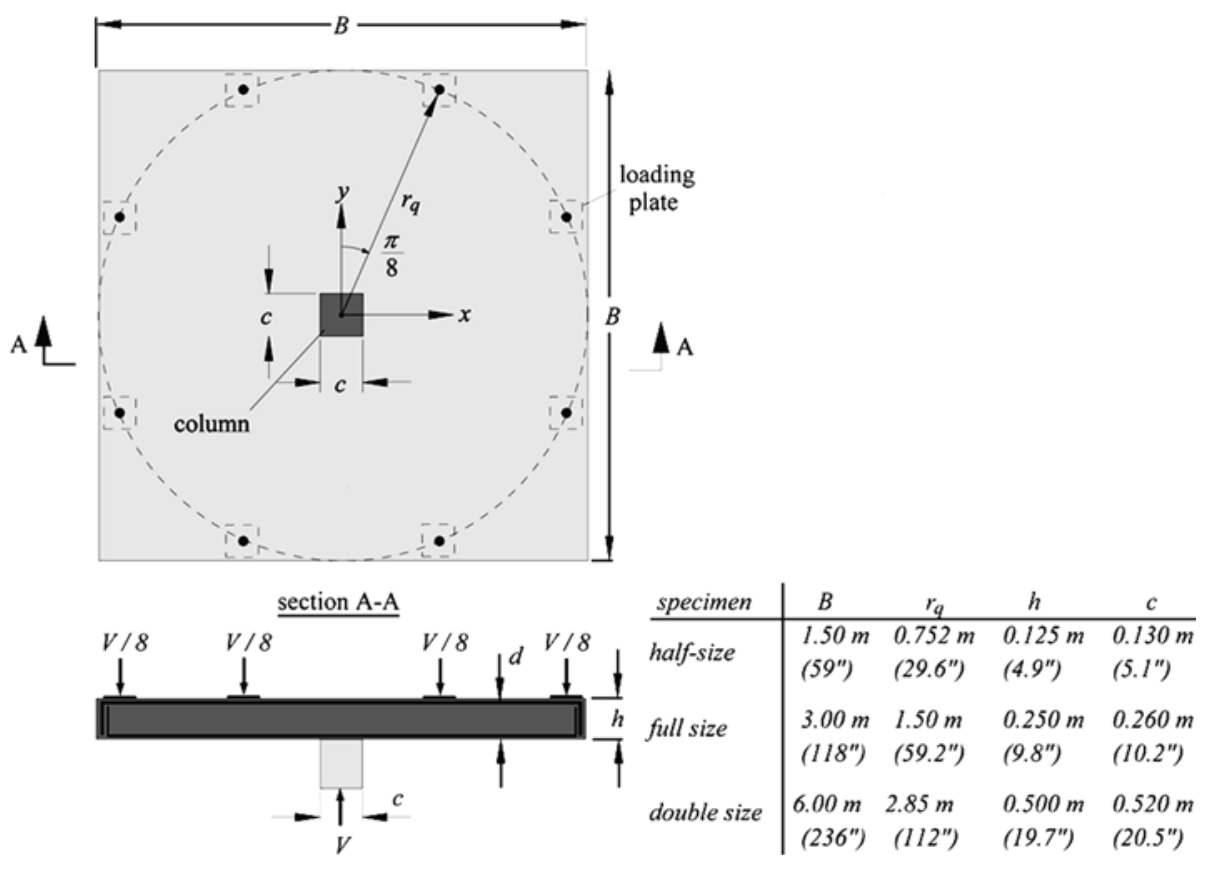

Fig. 2-Geometry of tested specimens. 


\section{Test specimens}

The test series consisted of 11 reinforced concrete square slabs representing internal slab-column connections without transverse reinforcement. The proportions of the flat slab represented by the specimens (Fig. 2), with a radial moment being zero at the perimeter (located at approximately $0.22 \ell$ from the column axis), correspond to a flat slab with a spanto-depth ratio $\ell / h$ of approximately 27 . The columns were square, with a side dimension $c$ slightly larger than the thickness $h$ of the slabs.

Table 1 shows the main parameters and characteristics of each specimen. Three main parameters were varied:

- The dimensions of the tested specimens: six full size specimens $(h=0.25 \mathrm{~m}$ [9.8 in.]), one double size specimen $(h=0.50 \mathrm{~m}$ [19.7 in.]), and four half-size specimens $(h=0.125 \mathrm{~m}[4.9 \mathrm{in}]$.$) . The variation in the$ scale of the specimens was made for all geometrical dimensions (Fig. 2). The double-size specimen (Fig. 3) is likely one of the largest (45 tons [100 kips]) ever tested in a laboratory;

- The amount of flexural reinforcement between 0.22 and $1.5 \%$ (refer to reinforcement layout in Fig. 4). Reinforcement was provided on the compression face in the amount of approximately $0.2 \%$ for all slabs except for the half-size specimens; and

- The maximum aggregate size: $16 \mathrm{~mm}$ (0.63 in.) for all slabs regardless of their thickness, except for Specimen PG-4, for which it was $4 \mathrm{~mm}$ (0.16 in.).

\section{Materials}

The mechanical properties of concrete were kept as constant as possible. Ordinary concrete with a mean cylinder compressive strength of $33 \mathrm{MPa}(4890 \mathrm{psi})$ at the age of testing was used (Table 1).

In all specimens except one, hot-rolled steel bars (with a pronounced yield plateau) were used. For Specimen PG-5, on the contrary, cold-worked steel bars (without a well defined yielding plateau) were used to investigate the influence of this parameter.

\section{Test setup and instrumentation}

The full-size specimens were loaded through eight concentrated forces acting on the perimeter of the specimen; the load was introduced using four hydraulic jacks placed

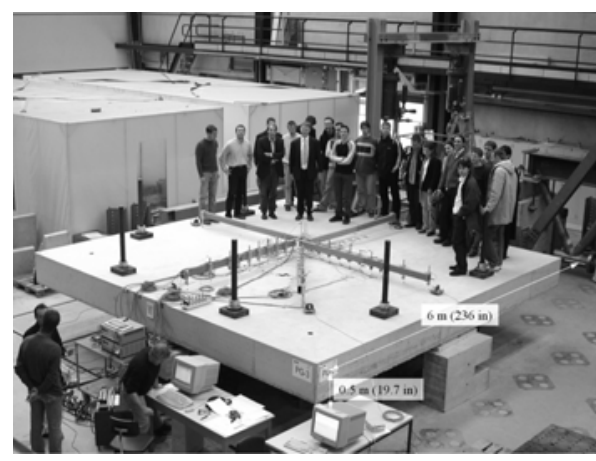

Fig. 3-Double-size specimen after testing.

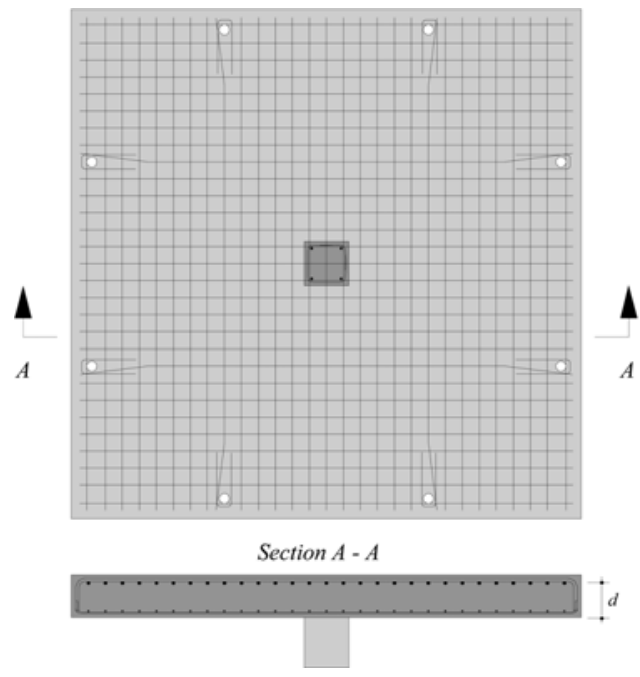

Fig. 4-Typical layout of flexural reinforcement (details given in Table 1).

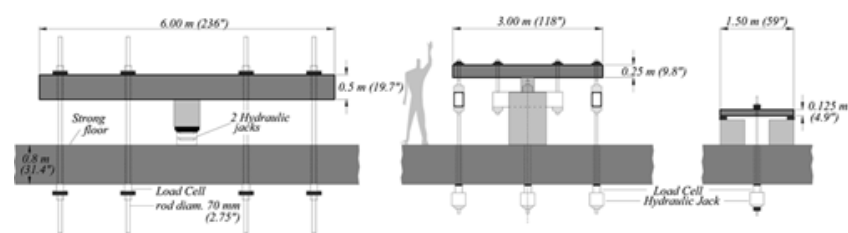

(a) double-size slab

(b) full size slabs

(c) half-size slabs

Fig. 5-Test setups for various types of specimens.

Table 1-Main parameters of test series

\begin{tabular}{|c|c|c|c|c|c|c|c|c|c|}
\hline \multirow{2}{*}{\multicolumn{2}{|c|}{ Specimen dimensions, $\mathrm{m}$ (in.) }} & \multicolumn{4}{|c|}{ Concrete } & \multicolumn{4}{|c|}{ Reinforcing steel } \\
\hline & & $d, \mathrm{~m}$ (in.) & $f_{c}, \mathrm{MPa}(\mathrm{psi})$ & $\begin{array}{c}\text { Age at testing, } \\
\text { days }\end{array}$ & $d_{g}, \mathrm{~mm}$ (in.) & Layout, mm (in.) & $\rho, \%$ & $f_{y}, \mathrm{MPa}(\mathrm{ksi})$ & $f_{u}, \mathrm{MPa}(\mathrm{ksi})$ \\
\hline \multirow{6}{*}{$\begin{array}{c}\text { Full-size specimens } \\
3.00 \times 3.00 \times 0.25 \\
(118 \times 118 \times 9.8)\end{array}$} & PG-1 & \multirow{6}{*}{$0.21(8.3)$} & $27.6(4000)$ & 33 & \multirow{2}{*}{$16(0.63)$} & Ø20@100 (No.3.9@3.9) & $1.50 \%$ & $573(83.1)$ & $656(95.1)$ \\
\hline & PG-2b & & $40.5(5870)$ & 240 & & Ø10@150 (No.5.9@5.9) & $0.25 \%$ & $552(80.1)$ & $612(88.8)$ \\
\hline & PG-4 & & $32.2(4670)$ & 28 & \multirow{2}{*}{$4(0.157)$} & $\varnothing 10 @ 150$ (No. 5.9@5.9) & $0.25 \%$ & $541(78.5)$ & $603(87.5)$ \\
\hline & PG-5 & & $29.3(4250)$ & 28 & & Ø10@115 (No.4.5@4.5) & $0.33 \%$ & $555(80.5)$ & $659(95.6)$ \\
\hline & PG-10 & & $28.5(4130)$ & 21 & \multirow{2}{*}{$16(0.63)$} & $\varnothing 10 @ 115$ (No.4.5@4.5) & $0.33 \%$ & $577(83.7)$ & $648(94.0)$ \\
\hline & PG-11 & & $31.5(4570)$ & 34 & & $\varnothing 16 / 18 @ 145$ (No.5.3/5.7@5.7) & $0.75 \%$ & $570(82.7)$ & $684(99.2)$ \\
\hline $\begin{array}{c}\text { Double-size specimen } \\
6.00 \times 6.00 \times 0.5 \\
(236 \times 236 \times 19.7)\end{array}$ & PG-3 & $0.456(17.9)$ & $32.4(4700)$ & 41 & $16(0.63)$ & Ø16@135 (No.5.3@5.3) & $0.33 \%$ & $520(75.4)$ & $607(88.0)$ \\
\hline \multirow{4}{*}{$\begin{array}{l}\text { Half-size specimens } \\
1.50 \times 1.50 \times 0.125 \\
\quad(59 \times 59 \times 4.9)\end{array}$} & PG-6 & $0.096(3.8)$ & $34.7(5030)$ & 99 & \multirow{4}{*}{$16(0.63)$} & Ø14@110 (No.4.3@4.3) & $1.50 \%$ & $526(76.3)$ & $607(88.0)$ \\
\hline & PG-7 & $0.1(3.9)$ & $34.7(5030)$ & 100 & & Ø10@105 (No.4.1@4.1) & $0.75 \%$ & $550(79.8)$ & $623(90.4)$ \\
\hline & PG-8* & $0.117(4.6)$ & $34.7(5030)$ & 100 & & Ø8@155 (No.6.1@6.1) & $0.28 \%$ & $525(76.1)$ & $586(85.0)$ \\
\hline & PG-9* & $0.117(4.6)$ & $34.7(5030)$ & 101 & & Ø8@196 (No.7.7@7.7) & $0.22 \%$ & $525(76.1)$ & $586(85.0)$ \\
\hline
\end{tabular}

*Effective thickness of slab is $0.130 \mathrm{~m}$ (5.1 in.). 


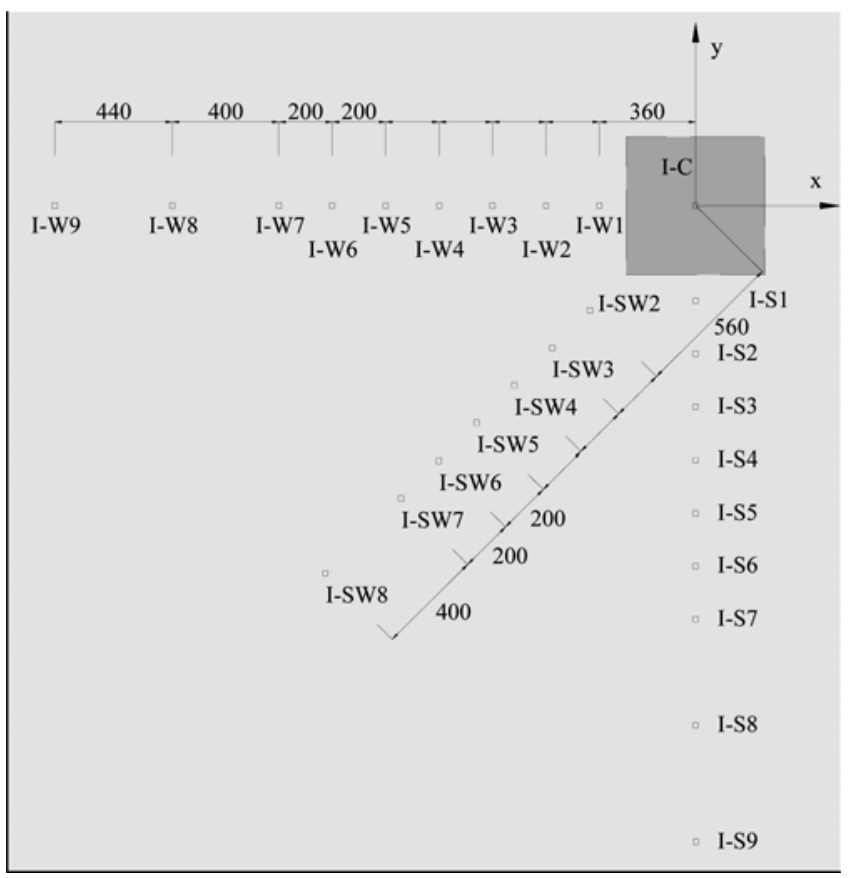

Fig. 6-Disposition of LVDTs at top surface of Specimen PG-3. (Note: dimensions in $\mathrm{mm}, 25.4 \mathrm{~mm}=1 \mathrm{in}$.)

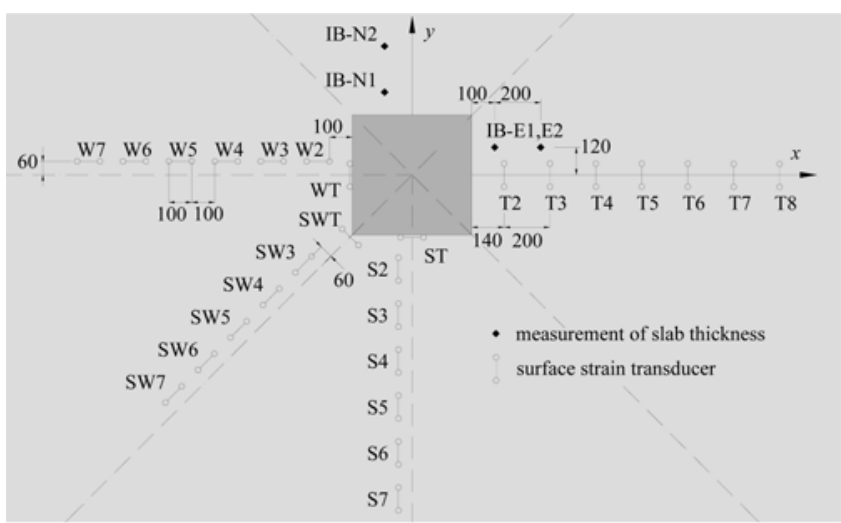

(a) Plan view

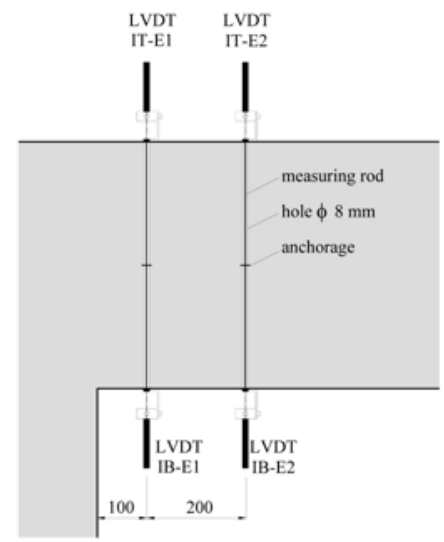

(b) Detail of the measurement of the plate thickness

Fig. 7-Disposition of strain transducers at surface of concrete (bottom face of slab) and of measurements of slab thickness for Specimen PG-3. (Note: dimensions in mm, $25.4 \mathrm{~mm}=1 \mathrm{in}$.) underneath the laboratory strong floor (Fig. 5(b)). The double-size specimen was loaded by hydraulic jacks placed directly underneath the column (Fig. 5(a)); the slab was restrained by eight strong bars along the perimeter. The small half-size specimens (Fig. 5(c)) were positioned upside down and simply supported on eight points; the column load was introduced by a tensile bar passing through a hole in the middle of the specimen and acting on a steel plate; the force was applied by a hydraulic jack placed underneath the strong floor. For simplicity's sake, all specimens are described in the following as if they had been tested in the normal position for a slab on a column (top is the tension face and bottom is the compression face). The effect of self-weight was accounted for in the values of the applied load.

More than 100 instruments were placed on the double-size specimen to measure in real time the applied forces, the vertical displacements at the top (Fig. 6) and at the bottom of the specimen, the slab rotations, the concrete surface strains (Fig. 7(a)), and the change in the thickness of the slab (Fig. 7(b)). The latter measurements were performed by LVDTs measuring the change in thickness of the slab between a fixed point at midheight and the top, repspectively bottom surface of the slab; these two values were subsequently added. They give information about the development of inclined shear cracks inside the specimen that are responsible for the punching failure. The layout of instrumentation shown in Fig. 6 and 7 corresponds to the double-size specimen. Some measurements were removed for the full-size specimens, whereas the number of measurements was drastically reduced for the half-size specimens. More details can be found in the test reports. ${ }^{13-15}$

\section{Loading}

During the punching test, the load was increased at a constant loading speed up to failure. It took approximately 1 hour from the beginning of the loading to failure in punching of each specimen.

\section{EXPERIMENTAL RESULTS}

\section{Deflections and surface strains}

Figure 8 shows the load-deflection curves for all tested specimens. After a short linear elastic branch, tangential and radial cracking strongly reduces the stiffness of the specimens,

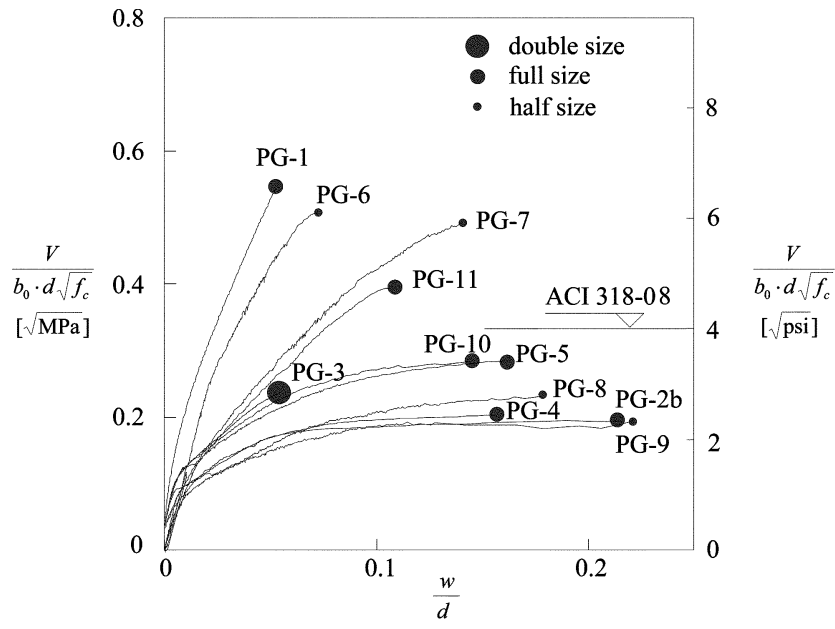

Fig. 8-Normalized load-deflection curve for all specimens (deflection $\mathrm{w}$ was measured between center of column and reaction points at perimeter). 
which is then significantly influenced by the flexural reinforcement ratio. For specimens with low reinforcement ratios and small slab depths, a plastic plateau can be observed for large deflections.

Figure 9(a) shows the deflected shape of Specimen PG-3 in radial direction for varying load levels. As previously
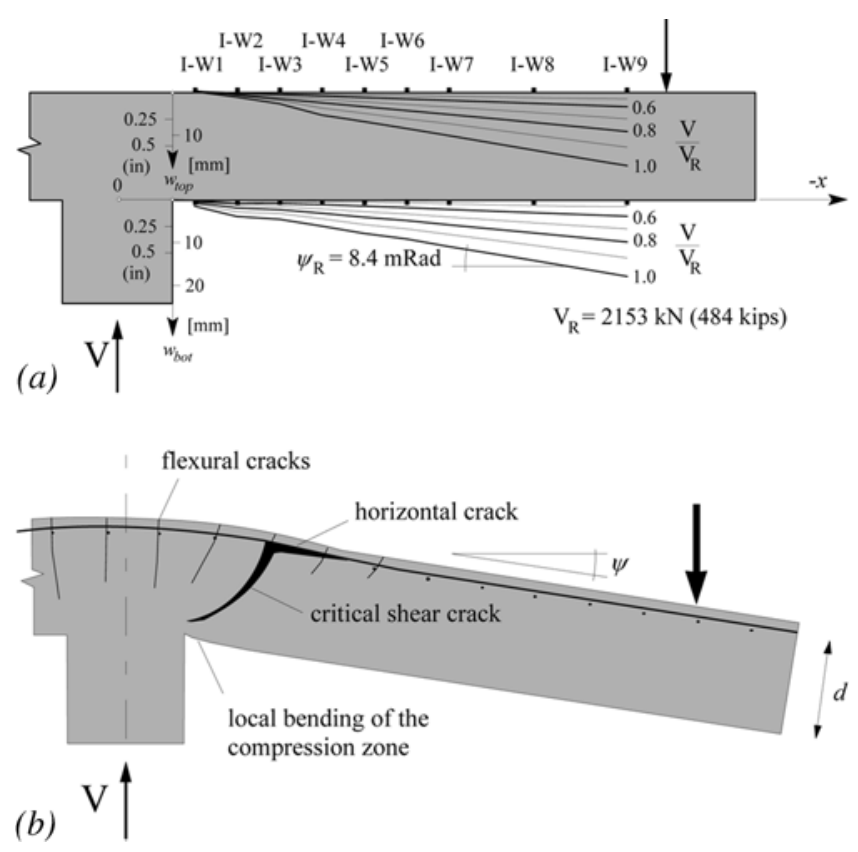

Fig. 9-Slab deflection during punching test: (a) measured values of $\mathrm{w}$ at top and bottom face of Slab PG-3 at various loading stages; and (b) interpretation of measurements according to critical shear crack theory (Appendix).

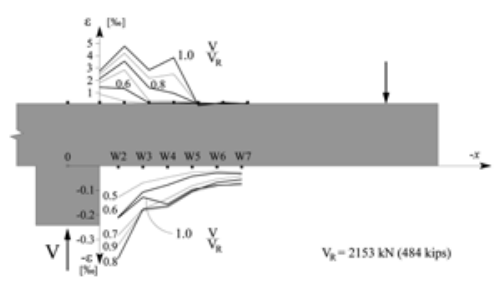

(a) radial strains as a function of the measurement location

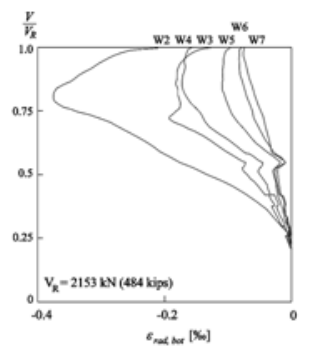

(b) evolution of the bottom radial strains as a function of the load
Fig. 10-Radial strains at surface of Specimen PG-3 (location of measurements [refer to Fig. 7]).
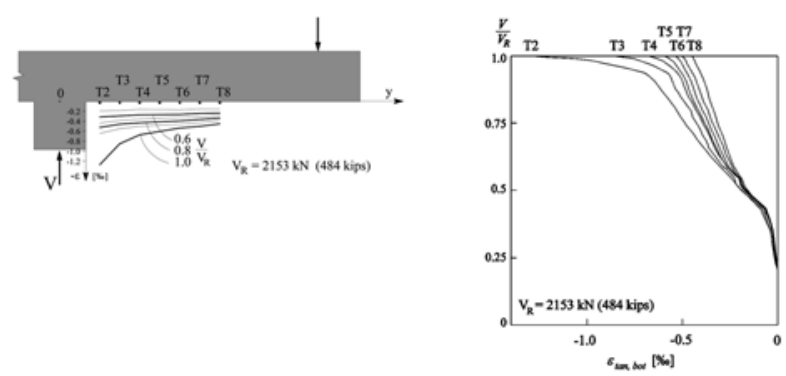

(a) tangential strains as a function of the $(b)$ evolution of the bottom tangential strains measurement location as a function of the load

Fig. 11-Tangential strains at surface, Specimen PG-3 (location of measurements [refer to Fig. 7]). observed by other researchers, the deflected shape is essentially conical in the part of the slab that lays outside the critical shear crack (Fig. 9(b)). The rotation $\psi$ of the slab can thus be used to characterize the deformation of the slab during the test.

Other interesting features of the deformed slab are shown in Fig. 9: the transition between the regions separated by the critical shear crack is different at the top and bottom faces of the specimen. At the top face, where the critical shear crack opens together with a horizontal crack along the reinforcement (Fig. 9(b)), the transition is marked by a local change of curvature (approximately between I-W2 and I-W4). At the bottom face, a local positive curvature develops close to the column due to local bending of the compression zone (at a location corresponding approximately to I-W1 to I-W3). As a result of this local curvature, the concrete at the surface decompresses near the column. This is confirmed by measurements of radial strains at the bottom surface of the specimen, shown in Fig. 10. This phenomenon has also been reported by other researchers. ${ }^{2}$

Tangential strains at the concrete bottom surface are shown in Fig. 11. They approximately follow a hyperbolic distribution along the $y$-axis (Fig. 11(a)). A strong increase in concrete strains in tangential direction is observed at the bottom surface close to the ultimate load (Fig. 11(b)).

\section{Cracking}

Cracking was observed at the top surface of the specimen, and cracks were marked without stopping the loading process. Figure 12 shows the observed final crack pattern at the top surface of Specimen PG-3.

The development of the inner critical shear crack is not visible. Its opening was consequently followed by recording changes of thickness of the plate using local measurements, as shown in Fig. 7(b). The results plotted in Fig. 13 for six representative cases indicate that the development of the inner crack does not start before 50 to $70 \%$ of the ultimate load, opening thereafter up to values of 1.0 to $1.5 \mathrm{~mm}$ ( 0.04 to 0.06 in.). This is consistent with observations of deflections and strains at the concrete surface (for instance, the decompression at the concrete surface near the column $^{9,11}$ due to the local bending of the compression zone [Fig. 9(b)]). After failure, each slab was sawed, allowing the observation of the final crack pattern shown in Fig. 14. It can

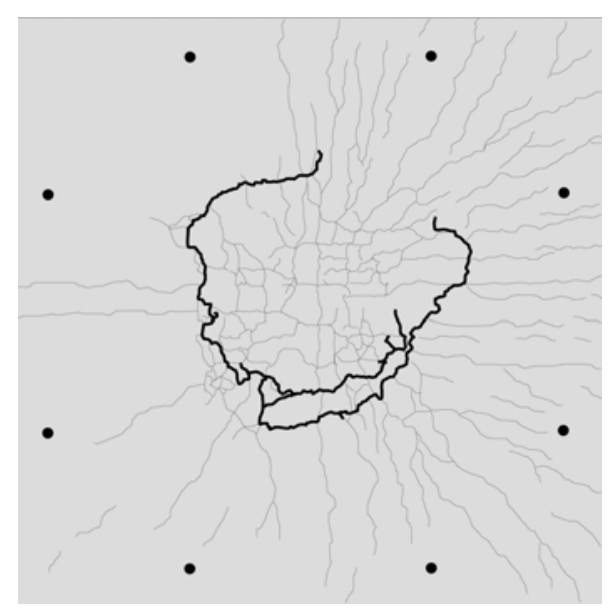

Fig. 12-Crack pattern after failure at top surface of Specimen PG 3, punching shear crack emphasized (cracks were not fully recorded in left part of slab). 
be observed that the large reinforcement ratio of Specimen PG-1 $(1.5 \%)$ led to a much flatter inclination of the critical shear crack in comparison with Specimens PG-2b and PG-5 $(0.25$ and $0.33 \%)$.

\section{Failure modes}

For all specimens, the final failure mode was punching shear, with a clearly delimited punching cone (Fig. 12 and 14). Two situations can, however, be distinguished: for tests with larger reinforcement ratios (Specimens PG-1, PG-6,

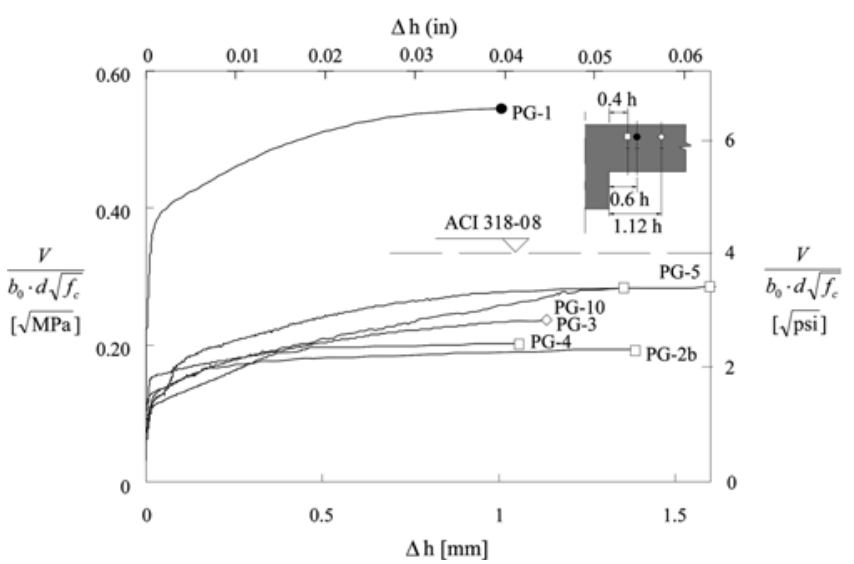

Fig. 13-Change of thickness of slab, indicative of development of critical shear crack, as a function of applied load.
Double-size specimen

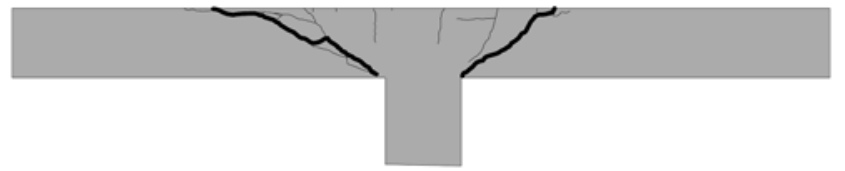

(a) PG-3 $(\rho=0.33 \%)$

Full-size specimens

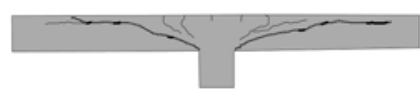

(b) PG-1 $(\rho=1.5 \%)$

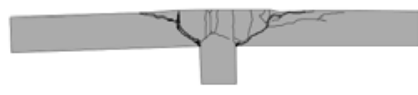

(d) PG-4 $(\rho=0.25 \%)$

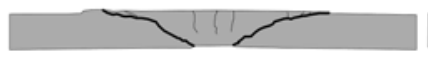

(f) PG-10 $(\rho=0.33 \%)$

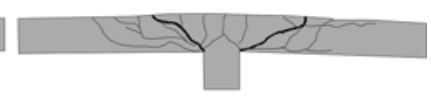

(c) PG-2b $(\rho=0.25 \%)$

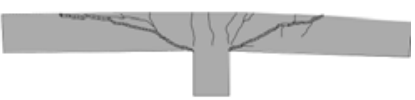

(e) PG-5 $(\rho=0.33 \%)$

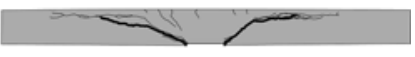

(g) PG-11 $(\rho=0.75 \%)$
Half-size specimens

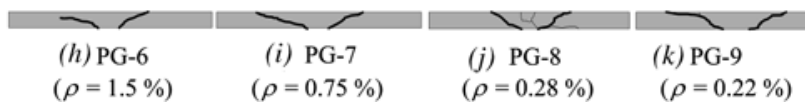

Fig. 14-Cross section of specimens after failure with critical shear crack emphasized.

Table 2-Test results (for specimens failing before reaching flexural capacity, estimated according to Eq. (7)) and comparison to $\mathrm{ACl} 318-0^{7}$ (considering control perimeters with rounded corners and with straight corners) and Eurocode $2^{8}$

\begin{tabular}{|c|c|c|c|c|c|c|c|c|c|}
\hline Specimen & $V_{R}, \mathrm{kN}$ (kips) & $V_{\text {flex }}, \mathrm{kN}$ (kips) & $V_{\text {test }} / V_{\text {flex }}$ & $\begin{array}{c}V_{A C I} \text { (rounded) } \\
\text { kN (kips) }\end{array}$ & $\begin{array}{c}V_{A C I} \text { (straight) } \\
\text { kN (kips) }\end{array}$ & $\begin{array}{c}V_{E C 2}, \mathrm{kN} \\
\text { (kips) }\end{array}$ & $\begin{array}{l}V_{\text {test }} / V_{A C I} \\
\text { (rounded) }\end{array}$ & $\begin{array}{l}V_{\text {test }} / V_{A C I} \\
\text { (straight) }\end{array}$ & $V_{\text {test }} / V_{E C 2}$ \\
\hline PG-1 & $1023(230)$ & $2241(504)$ & 0.46 & $625(140)$ & $691(155)$ & $950(213)$ & 1.64 & 1.48 & 1.08 \\
\hline PG-11 & $763(172)$ & $1226(275)$ & 0.63 & $668(149)$ & 739 (166) & 788 (177) & 1.14 & 1.03 & 0.97 \\
\hline PG-3 & $2153(484)$ & $2576(579)$ & 0.84 & 3039 (683) & $3378(757)$ & $2340(526)$ & 0.71 & 0.64 & 0.92 \\
\hline PG-6 & $238(54)$ & $441(99)$ & 0.54 & $155(35)$ & $170(38)$ & $221(50)$ & 1.54 & 1.40 & 1.08 \\
\hline PG-7 & $241(54)$ & $272(61)$ & 0.89 & $164(37)$ & $181(41)$ & $189(43)$ & 1.47 & 1.33 & 1.27 \\
\hline & & & & & & Average & 1.30 & 1.18 & 1.06 \\
\hline & & & & & & $\begin{array}{l}\text { Coefficient of } \\
\text { variation }\end{array}$ & 0.29 & 0.29 & 0.13 \\
\hline & & & & & & Minimum & 0.71 & 0.64 & 0.92 \\
\hline
\end{tabular}

Table 3-Comparison of test results to strength and rotation capacities predicted by critical shear crack theory

\begin{tabular}{|c|c|c|c|c|c|c|c|c|}
\hline Specimen & $V_{R}, \mathrm{kN}$ (kips) & $\psi_{R}, \mathrm{mRad}$ & $V_{\text {flex }}, \mathrm{kN}$ (kips) & $V_{\text {test }} / V_{\text {flex }}$ & $V_{C S C T}, \mathrm{kN}$ (kips) & $\psi_{C S C T}, \mathrm{mRad}$ & $V_{\text {test }} / V_{C S C T}$ & $\psi_{R} / \psi_{C S C T}$ \\
\hline PG-1 & $1023(230)$ & 8.9 & $2241(504)$ & 0.46 & $841(188)$ & 6.8 & 1.22 & 1.30 \\
\hline PG-2b & $440(99)$ & 30.1 & $419(94)$ & 1.05 & $420(94)$ & 31.0 & 1.05 & 0.97 \\
\hline PG-4 & $408(92)$ & 24.4 & $409(92)$ & 1.00 & $344(77)$ & 21.7 & 1.19 & 1.12 \\
\hline PG-5 & $550(124)$ & 24.7 & $541(122)$ & 1.04 & $455(102)$ & 22.2 & 1.21 & 1.11 \\
\hline PG-10 & $540(121)$ & 22.3 & $562(126)$ & 0.96 & 454 (101) & 21.8 & 1.19 & 1.02 \\
\hline PG-11 & $763(172)$ & 10 & $1226(275)$ & 0.63 & $682(153)$ & 12.2 & 1.12 & 0.82 \\
\hline PG-3 & $2153(484)$ & 8.4 & $2576(579)$ & 0.84 & $1730(388)$ & 13.8 & 1.24 & 0.61 \\
\hline PG-6 & $238(54)$ & 11.7 & $441(99)$ & 0.54 & $231(52)$ & 11.4 & 1.03 & 1.03 \\
\hline PG-7 & $241(54)$ & 22.3 & $272(61)$ & 0.89 & 197 (44) & 18.6 & 1.22 & 1.20 \\
\hline PG-8 & $140(31)$ & 31.8 & $137(31)$ & 1.02 & $137(30)$ & 42.8 & 1.02 & 0.74 \\
\hline \multirow[t]{3}{*}{ PG-9 } & $115(26)$ & 42.1 & $109(24)$ & 1.06 & $109(24)$ & 58.7 & 1.06 & 0.72 \\
\hline & & & & & & Average & 1.14 & 0.97 \\
\hline & & & & & & $\begin{array}{l}\text { Coefficient of } \\
\text { variation }\end{array}$ & 0.08 & 0.23 \\
\hline
\end{tabular}


PG-7, and PG-11), failure occurred while some of the reinforcement had yielded over the column and the remaining part was still elastic. In the load-deflection curve of Fig. 8, these specimens failed without having reached their plastic plateau. On the contrary, for tests with lower reinforcement ratios (Specimens PG2b, PG-4, PG-5, PG-8, PG-9, and PG-10), the specimens reached their plastic plateau and punching failure occurred with large plastic deformations at the onset of the yield-line mechanism.

The double-size Specimen PG-3 constituted an interesting exception: whereas it had a low amount of reinforcement $(\rho=$ $0.33 \%$ ), it clearly did not reach its plastic plateau and failed in punching at a load lower than the slab's flexural capacity.

\section{Effect of type of reinforcement}

Specimens PG-10 and PG-5 were identical, except that the latter used cold-worked steel bars without a well-defined yield plateau. The former, like all the other specimens, used a steel with a well-defined plateau. No significant difference in the behavior (strength and deformation at failure) was observed, however (Fig. 8).

\section{COMPARISON WITH DESIGN CODES}

Table 2 summarizes the results of the tests where the flexural capacity $V_{\text {flex }}$ was not reached. These results are compared with the values predicted by the punching shear formulations of ACI 318- $08^{7}$ (calculated with rounded and straight corners for the perimeter of the critical section) and of Eurocode 2. ${ }^{8}$

For slabs with large reinforcement ratios (failing in punching before reaching the yield plateau in the loadrotation curve), the predictions given by ACI $318-08^{7}$ are, in general, conservative. For the double-size Specimen PG-3 (also failing before reaching the yield plateau), however, the punching shear strength according to ACI $318-08^{7}$ is overestimated by almost $30 \%$ if a perimeter with rounded corners is considered, and by almost $36 \%$ if a simplified perimeter with straight corners is considered. These significant differences are due to the fact that the ACI punching shear formulation accounts neither for the role of the reinforcement ratio (although the nominal punching shear strength decreases for decreasing ratios of the flexural reinforcement as clearly shown by test results presented in this paper) nor for the size of the member (although the nominal punching shear strength decreases for increasing sizes of the members, as clearly shown by Specimen PG-3 compared with Specimens PG-10 or PG-5).

The predictions of Eurocode $2^{8}$ are much closer to the measured values than those of ACI $318-08,{ }^{7}$ with a smaller coefficient of variation (0.13). For the large Specimen PG-3, however, the strength was also overestimated.

\section{VALIDATION OF FAILURE CRITERION OF CRITICAL SHEAR CRACK THEORY}

The results of the test series, together with 88 other tests taken from the scientific literature ${ }^{1-3,16-21}$ are compared in Fig. 15 to the failure criterion of the critical shear crack theory ${ }^{9,12}$ (refer to the Appendix). The abscissa is proportional to the opening of the critical shear crack, accounting for the thickness $d$ of the slab and its rotation at failure $\psi$, and corrected for the maximum aggregate size $d_{g}$. This figure shows a very good agreement between the measured loads and rotations at failure and the failure criterion of the critical shear crack theory, for the results of the current test series (Fig. 15(a)) as well as for previously published results (Fig. 15(b) and (c), which include tests from the literature as well as the present test series). It is interesting to note that most test results available in the scientific literature correspond to specimens failing in punching shear for small values on
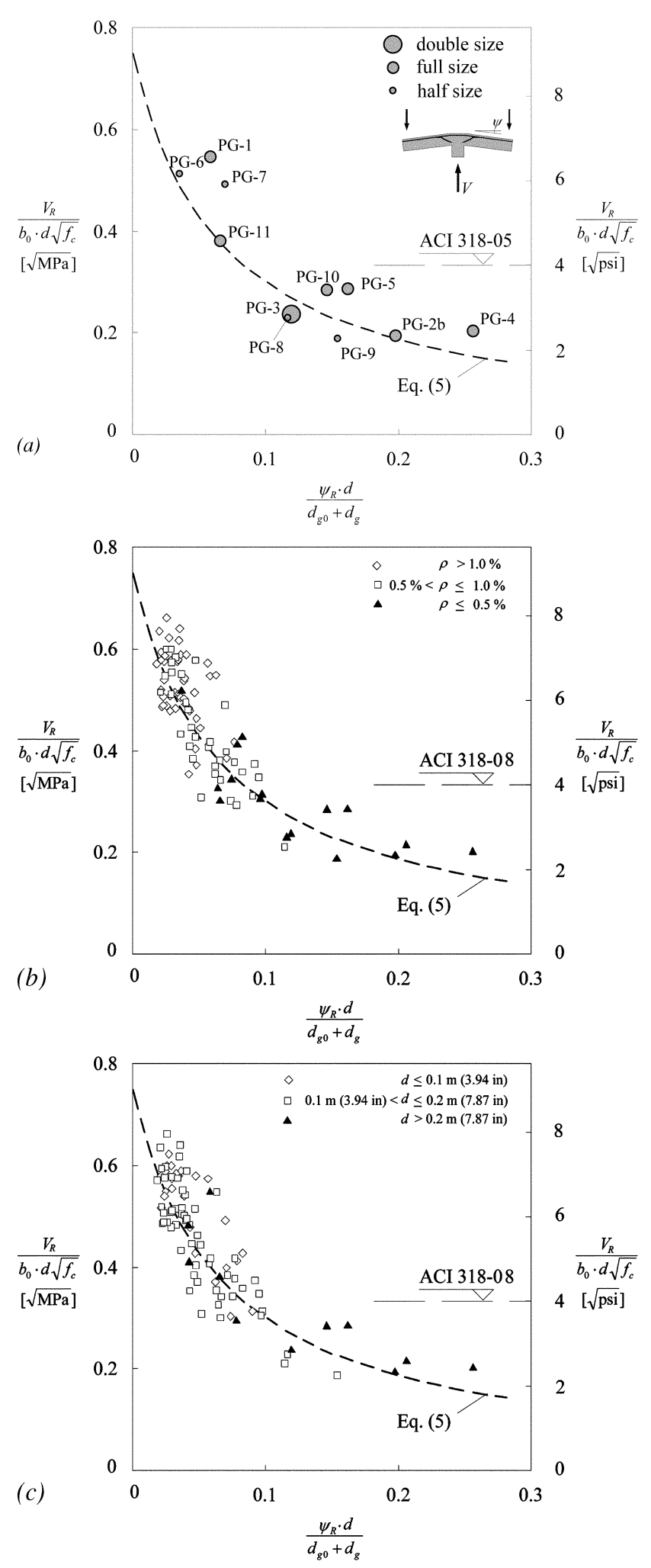

Fig. 15-Results of 99 punching tests: 11 from present test series and 88 tests taken from scientific literature ${ }^{1-3,16-21}$ compared with failure criterion of critical shear crack theory: (a) results of present test series (11 tests); (b) 99 tests with identification of reinforcement ratio; and (c) 99 tests with identification of effective depth. 
the abscissa, typically with large reinforcement ratios (Fig. 15(b)) and small sizes (Fig. 15(c)), whereas scarce data are found for large values on this abscissa (corresponding to low reinforcement ratios or large thicknesses). The results of the present test campaign (mostly with large values on the abscissa) cover this zone and thus validate the failure criterion for such cases.

Table 3 compares the strength and rotation capacity predictions of the critical shear crack theory (using the formulas detailed in the Appendix) to the 11 tests presented in this paper. A very good agreement is obtained in terms of strength (with safe predictions for Specimen PG-3 and with a rather small value of the coefficient of variation) and a satisfactory prediction in terms of the rotation capacity. The results of Table 3 and Fig. 15 confirm that the failure criterion is also valid for slabs undergoing significant plastic strains in the flexural reinforcement prior to punching. This is justified by the fact that the critical shear crack theory accounts for a decrease in the nominal shear strength for increasing openings of the critical shear crack (which in turn can be expressed as a function of the rotation of the slab [refer to the Appendix]). Thus, although a slab may have a sufficient shear strength to reach its flexural strength, as the rotations of the slab increase in the plastic plateau, its punching shear strength diminishes and this eventually leads to a punching shear failure, which reduces its deformation capacity (refer to, for instance, the punching shear cones of Fig. 14 for Specimens PG-8, PG-9, PG-2b, and PG-4 with low reinforcement ratios).

In addition, it can be noted that the failure criterion correctly accounts for the effect of aggregate size. This is verified against the 88 tests taken from the scientific literature performed with different aggregate sizes ${ }^{1-3,16-21}$ and by Specimens PG-2b and PG-4 presented herein. These two tests have the same amount of reinforcement and the same size, but different maximum aggregate size of $16 \mathrm{~mm}$ (0.63 in.) for Specimen PG-2b and 4 mm (0.157 in.) for Specimen PG-4. The deformation at failure of the slab with smaller aggregate is smaller than that of the slab with coarser aggregate. Additional research on this topic (focusing also on specimens with large flexural reinforcement ratios) is needed, however, before consistent conclusions can be drawn.

\section{SUMMARY AND CONCLUSIONS}

A series of 11 punching tests on flat slabs were performed. The tests are useful to complement available punching test series performed in the past, as the tests presented in this paper systematically explore the domain of slabs with low flexural reinforcement ratios.

1. The tests have confirmed that, due to size effect, the punching strength decreases with increasing slab thickness. At the same time, the deformation at failure decreases;

2. Detailed measurements at the top and bottom faces of the specimens have allowed the description of the development of the critical shear crack leading to punching failure and of the slab kinematics. On that basis, the hypotheses the critical shear crack theory is based on 9,12 are confirmed;

3. For thick slabs with low reinforcement ratios, ACI 318-08 ${ }^{7}$ is less conservative than shown by Specimen PG-3 of this campaign (slab thickness equal to $0.5 \mathrm{~m}$ [19.7 in.]). The coefficient of variation of the tests is fairly large as well (0.29). The values given by Eurocode $2^{8}$ are in better correlation with the experimental results. The failure load predicted for Specimen PG-3 is unsafe as well; and
4. The test series demonstrate that the failure criterion of the critical shear crack theory 9,12 is applicable both for slabs with and without significant plastic deformations in the flexural reinforcement (that is, with low or large reinforcement ratios), correctly describing both the strength and the deformation at failure.

\section{ACKNOWLEDGMENTS}

The work presented in this paper was funded by the Association of the Swiss Cement Industry (cemsuisse) and by the Holcim cement and concrete supplier. The authors are appreciative of the support received.

\begin{tabular}{|c|c|}
\hline & ON \\
\hline$B$ & $=$ side dimension of test specimen \\
\hline$V$ & $=$ shear force \\
\hline$V_{A C I}$ & $=$ nominal punching shear strength according to ACI $318-08^{7}$ \\
\hline$V_{C S C T}$ & $\begin{array}{l}=\text { nominal punching shear strength according to critical shear } \\
\text { crack theory }\end{array}$ \\
\hline$V_{E C 2}$ & $=$ nominal punching shear strength according to Eurocode $2^{8}$ \\
\hline$V_{\text {flex }}$ & $=$ shear force associated with flexural capacity of slab \\
\hline$V_{R}$ & $=$ nominal punching shear strength \\
\hline$V_{\text {test }}$ & $=$ experimental punching shear strength \\
\hline$b_{0}$ & 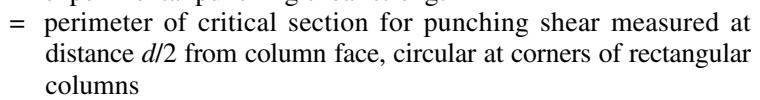 \\
\hline$b_{0, E C 2}$ & $\begin{array}{l}=\text { perimeter of critical section for punching shear according to } \\
\text { Eurocode } 2 \text {, measured at distance } 2 d \text { from column face, circular } \\
\text { at corners of rectangular columns }\end{array}$ \\
\hline$c$ & $=$ column size \\
\hline$d$ & $\begin{array}{l}=\text { distance from extreme compression fiber to centroid of longitu- } \\
\text { dinal tensile reinforcement }\end{array}$ \\
\hline$d_{g}$ & $=$ maximum diameter of aggregate \\
\hline$d_{g 0}$ & $=$ reference aggregate size $(16 \mathrm{~mm}[0.63 \mathrm{in}])$. \\
\hline$E_{s}$ & $=$ modulus of elasticity of reinforcement \\
\hline$f_{c}$ & $=$ compressive strength of concrete (cylinder) \\
\hline$f_{c}^{\prime}$ & $=$ specified compressive strength of concrete (cylinder) \\
\hline$f_{c k}$ & $=$ characteristic compressive strength of concrete (cylinder) \\
\hline$f_{y}$ & $=$ yield strength of reinforcement \\
\hline$f_{u}$ & $=$ tensile strength of reinforcement \\
\hline$h$ & $=$ slab thickness \\
\hline$\ell$ & $=$ span of the slab $\left(\ell_{1}\right.$ and $\ell_{2}:$ spans in orthogonal directions $)$ \\
\hline$m_{R}$ & $=$ nominal moment capacity per unit width \\
\hline$r_{q}$ & $=$ radius of load introduction at perimeter \\
\hline$r_{s}$ & $=$ plastic radius around column \\
\hline$w$ & $\begin{array}{l}=\text { deflection of test slab, measured between center of column and } \\
\text { reaction points at perimeter }\end{array}$ \\
\hline$w_{c}$ & $=$ opening of critical shear crack \\
\hline$w_{\text {bot }}$ & $=$ deflection of bottom surface of slab \\
\hline$w_{\text {top }}$ & $=$ deflection of top surface of slab \\
\hline$x, y$ & $=$ coordinates \\
\hline$\gamma_{c}$ & $\begin{aligned}= & \text { partial safety factor for concrete (according to European practice, } \\
& \gamma_{c}=1.5 \text { ) }\end{aligned}$ \\
\hline$\Delta h$ & $=$ local change of thickness of slab \\
\hline$\varepsilon$ & $=$ strain \\
\hline$\varepsilon_{\text {rad,bot }}$ & $=$ radial strain at bottom face of specimen \\
\hline$\varepsilon_{\text {tan,bot }}$ & $=$ tangential strain at bottom face of specimen \\
\hline & $\begin{aligned}= & \text { strength reduction factor (according to North-American practice, } \\
& \phi=0.75 \text { for shear) }\end{aligned}$ \\
\hline$\lambda$ & $\begin{aligned} &= \text { modification factor for lightweight concrete, taken as unity for } \\
& \text { normalweight concrete }\end{aligned}$ \\
\hline$\rho$ & $=$ flexural reinforcement ratio \\
\hline$\xi$ & $=$ size effect factor according to Eurocode $2^{8}$ \\
\hline$\psi$ & $=$ rotation of slab outside column region \\
\hline$\psi_{C S C T}$ & $=$ rotation of slab at failure according to critical shear crack theory \\
\hline & $=$ rotation of slab at failure \\
\hline
\end{tabular}

\section{REFERENCES}

1. Elstner, R. C., and Hognestad, E.,"Shearing Strength of Reinforced Concrete Slabs," ACI Journal, Proceedings V. 53, No. 2, Feb. 1956, pp. 29-58.

2. Kinnunen, S., and Nylander, H.,"Punching of Concrete Slabs without Shear Reinforcement," No. 158, Transactions of the Royal Institute of Technology, Stockholm, Sweden, 1960, 112 pp.

3. Moe, J.,"Shearing Strength of Reinforced Concrete Slabs and Footings under Concentrated Loads," Bulletin D47, Portland Cement Association, Skokie, IL, 1961, 144 pp. 
4. Silfwerbrand, J., and Hassanzadeh, G., eds., International Workshop on Punching Shear Capacity of RC Slabs, Royal Institute of Technology, Stockholm, Sweden, 2000, 527 pp.

5. fib, "Punching of Structural Concrete Slabs," fib Bulletin 12, Lausanne, Switzerland, 2001, 307 pp.

6. Polak, M. A., ed., Punching Shear in Reinforced Concrete Slabs, SP-232, American Concrete Institute, Farmington Hills, MI, 2005, 302 pp.

7. ACI Committee 318,"Building Code Requirements for Structural Concrete (ACI 318-08) and Commentary," American Concrete Institute, Farmington Hills, MI, 2005, 465 pp.

8. CEN, "Eurocode 2-Design of Concrete Structures: Part 1-1General Rules and Rules for Buildings," EN 1992-1-1, Brussels, Belgium, 2004, 225 pp.

9. Muttoni, A.,"Punching Shear Strength of Reinforced Concrete Slabs without Transverse Reinforcement," ACI Structural Journal, V. 105, No. 4, July-Aug. 2008, pp. 440-450.

10. Stein, T.; Ghali, A.; and Dilger, W. H.,"Distinction between Punching and Flexural Failure Modes of Flat Plates," ACI Structural Journal, V. 104, No. 3, May-June 2007, pp. 357-365.

11. Muttoni, A., and Schwartz, J., Behavior of Beams and Punching in Slabs without Shear Reinforcement, V. 62, IABSE Colloquium, Stuttgart, Germany, 1991, pp. 703-708.

12. Muttoni A.,"Shear and Punching Strength of Slabs without Shear Reinforcement," Beton-und Stahlbetonbau, V. 98, No. 2, Berlin, Germany, 2003, pp. 74-84. (in German)

13. Guandalini, S., and Muttoni, A.,"Symmetrical Punching Tests on Slabs without Transverse Reinforcement," Test Report, École Polytechnique Fédérale de Lausanne, Lausanne, Switzerland, 2004, 85 pp. (in French)

14. Guandalini, S., "Symmetric Punching of Reinforced Concrete Slabs," doctoral thesis, École Polytechnique Fédérale de Lausanne, Lausanne, Switzerland, 2005, 289 pp. (in French)

15. Guidotti, R.; Fernández Ruiz, M.; and Muttoni, A.,"Influence of Axial Load on the Punching Strength of Reinforced Concrete Slabs," Test Report, École Polytechnique Fédérale de Lausanne, Switzerland, 2007, 64 pp. (in French)

16. Tolf, P.,"Influence of the Slab Thickness on the Strength of Concrete Slabs at Punching-Tests With Circular Slabs," Bulletin 146, Royal Institute of Technology, Department of Structural Mechanics and Engineering, Stockholm, Sweden, 1988, 64 pp. (in Swedish)

17. Hallgren, M.,"Punching Shear Capacity of Reinforced High Strength Concrete Slabs," doctoral thesis, KTH Stockholm, Stockholm, Sweden, 1996.

18. Nylander, H., and Sundquist, H.,"Punching of Bridge Slabs with Non-Prestressed Reinforcement on Columns," Test Report KTH, No. 104, Stockholm, Sweden, 1972, 64 pp. (in Swedish)

19. Kinnunen, S.; Nylander, H.; and Tolf, P.,"Plattjocklekens Inverkan Pa Betongplattors Hallfasthet Vid Genomstansning. Försök Med Rektangulära Plattor," Test Report KTH, No. 137, Stockholm, Sweden, 1980, 73 pp. (in Swedish)

20. Ramdane, K.-E.,"Punching Shear of High Performance Concrete Slabs," Proceedings of the Fourth International Symposium on Utilization of High-Strength/High Performance Concrete, V. 3, Paris, France, 1996, pp. 1015-1026.

21. Hassanzadeh, G., and Farhang, A.,"Strengthening of Bridge Slabs with Respect to Punching," master's Thesis, KTH, Stockholm, Sweden, 1995, 134 pp. (in Swedish)

\section{APPENDIX: FUNDAMENTALS OF CRITICAL SHEAR CRACK THEORY}

As the interpretation of the test results relies on the critical shear crack theory, a short introduction to its fundamentals is presented herein. The critical shear crack theory ${ }^{9,12}$ is based on the assumption that the shear strength of members without transverse reinforcement is governed by the width and by the roughness of an inclined shear crack that develops through the inclined compression strut carrying shear. In two-way slabs, the width $w_{c}$ of the critical shear crack is assumed proportional to the slab rotation $\psi$ times the effective depth $d$ of the member (Fig. 9(b))

$$
w_{c} \propto \psi \cdot d
$$

Based on these assumptions, the following failure criterion ${ }^{12}$ has been derived for the punching shear strength of flat slabs without stirrups

$$
\begin{gathered}
\frac{V_{R}}{b_{0} d \sqrt{f_{c}}}=\frac{3 / 4}{1+15 \frac{\psi \cdot d}{d_{g 0}+d_{g}}} \text { (in SI units; MPa, mm) } \\
\frac{V_{R}}{b_{0} d \sqrt{f_{c}}}=\frac{9}{1+15 \frac{\psi \cdot d}{d_{g 0}+d_{g}}} \text { (in U.S. customary units; psi, in.) }
\end{gathered}
$$

where $V_{R}$ is the shear strength, $b_{0}$ is a control perimeter at $d / 2$ from the edge of the column, $d$ is the effective depth of the member, $f_{c}$ is the compressive strength of the concrete, $d_{g}$ is the maximum size of the aggregate (accounting for the roughness of the lips of the cracks), and $d_{g 0}$ is a reference aggregate size equal to $16 \mathrm{~mm}$ (0.63 in.). This criterion provides a suitable estimate of both the strength $V_{R}$ and deformation capacity $\psi_{R}$ of a slab compared with a wide range of test results as shown by Muttoni. ${ }^{9}$

The failure load is obtained at the intersection of the failure criterion of Eq. (A-2) with the load-deflection curve of the slab. The load-rotation relationship of the slab can be obtained using both analytical ${ }^{9}$ or numerical ${ }^{14}$ approaches. For practical purposes, it can be approximated by the following expression ${ }^{9}$

$$
\psi=1.5 \frac{r_{s}}{d} \cdot \frac{f_{y}}{E_{s}}\left(\frac{V}{V_{\text {flex }}}\right)^{3 / 2}
$$

where $r_{s}$ is the radius of the slab. For the tests presented in this paper (corresponding to the yield line pattern of Fig. A), $r_{s}$ can be approximated as $r_{s} \approx B / 2$.

The flexural strength $V_{\text {flex }}$ of the slab specimen can be estimated by the yield-line method for a uniformly reinforced slab loaded as shown in Fig. A

$$
V_{f l e x}=\frac{4 m_{R}}{r_{q}\left(\cos \frac{\pi}{8}+\sin \frac{\pi}{8}\right)-c} \cdot \frac{B^{2}-B c-c^{2} / 4}{B-c}
$$

where $m_{R}$ is the nominal moment capacity.

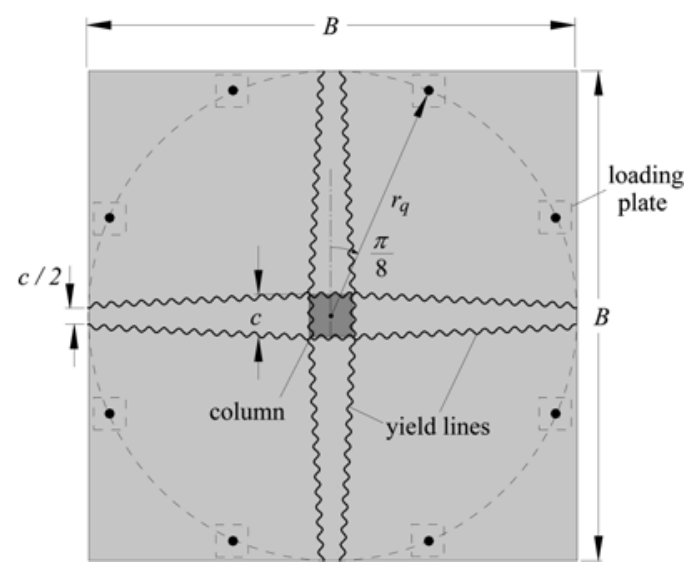

Fig. A-Yield-line pattern considered for tested slabs. 